\title{
Heart rate variability responses to a combined exercise training program: correlation with adiposity and cardiorespiratory fitness changes in obese young men
}

\author{
Jatuporn Phoemsapthawee', Piyapong Prasertsri', Naruemon Leelayuwat ${ }^{3,4, *}$ \\ 'Department of Sports Science and Health, Faculty of Sports Science, Kasetsart University, Nakhon Pathom, Thailand \\ ${ }^{2}$ Faculty of Allied Health Sciences, Burapha University, Chonburi, Thailand \\ ${ }^{3}$ Department of Physiology, Faculty of Medicine, Khon Kaen University, Khon Kaen, Thailand \\ ${ }^{4}$ Exercise and Sport Sciences Development and Research Group, Khon Kaen University, Khon Kaen, Thailand
}

\begin{abstract}
Although the influence of adiposity indices and cardiorespiratory fitness (CRF) on heart rate variability (HRV) has been demonstrated extensively, the causal link between the changes in adiposity as well as in CRF and the alterations in cardiac autonomic function is unclear. Thus, this study aimed to assess the correlation between the changes in adiposity and CRF and the alterations in HRV after 12-week exercise training. Twenty obese sedentary men aged $20.5 \pm 1.2$ years were randomly assigned into 2 groups ( $n=10$ each): the control (CG) and the exercise group (EG). The EG trained 60 min of combined aerobic, anaerobic and strengthening exercise, 4 sessions/wk for 12 weeks, whilst the CG remained relatively inactive. Measurements of resting HRV, body composition, and peak oxygen consumption $\left(\mathrm{VO}_{2 \text { peak }}\right)$ were obtained at baseline and after the 12-week training program. Compared with CG, the exercise training
\end{abstract}

significantly reduced adiposity indices and improved vagal-related HRV variables and $\mathrm{VO}_{\text {2peak. }}$. Significant correlations were observed between changes in $\mathrm{HRV}$ variables and adiposity indices and $\mathrm{VO}_{2 \text { peak }}$ changes. Stepwise regression analysis revealed that changes in a Poincaré plot index (SD1/SD2 ratio) predicted $32.4 \%$ of the variance in the relative $\mathrm{VO}_{2 \text { peak }}$ changes. These findings suggest that obese sedentary young men achieved significant improvements in vagal activity, adiposity indices and aerobic fitness after the exercise training. The higher reduction in fat mass, especially central obesity, the greater alteration of vagal modulation. Moreover, the alteration in resting HRV is a possible predictor for adaptations to exercise training in obese sedentary young men.

Keywords: Exercise training, Central obesity, Heart rate, Exercise test

\section{INTRODUCTION}

The prevalence of obesity continues to rise and presents as a major public health concern in Thailand. Essentially, the prevalence of obesity in the 18-24 age group has been doubled for over 10 years (Aekplakorn and Mo-Suwan, 2009). Obesity rises the risks of cardiovascular diseases (CVD) and all-cause of mortality (Jensen et al., 2014). Obesity is also associated with dysregulation of cardiac autonomic function (Lindmark et al., 2005). It has been reported that autonomic dysregulation is an important mediator in the development of CVD risks in obese individuals (Lindmark et al., 2005; Sheema and Malipatil, 2015). Assessment of heart rate variability (HRV) has been recognized as a noninvasive method for assessing cardiac autonomic modulation (Task Force of the European Society of Cardiology and the North American Society of Pacing and Electrophysiology, 1996). Reduced HRV has been associated with higher weight and adiposity (Gutin et al., 2005; Tian et al., 2015). On the other hand, weight reduction via exercise training and/or calorie restriction in obese subjects has been suggested to improve vagal activity (Facchini et al., 2003; Ito et al., 2001; Tian et al., 2015). The increase in vagal activity in response to weight loss program may consistently contribute to reduce the risk of cardiovascular morbidity and of sudden cardiac death (Facchini et al., 2003; Gutin et al., 2005; Ito et al., 2001).
${ }^{*}$ Corresponding author: Naruemon Leelayuwat

(iD) https://orcid.org/0000-0002-7189-1475

Department of Physiology, Faculty of Medicine, Khon Kaen University,

Khon Kaen 40002, Thailand

E-mail: naruemon.leelayuwat@gmail.com

Received: November 5, 2018 / Accepted: December 19, 2018
This is an Open Access article distributed under the terms of the Creative Commons Attribution Non-Commercial License (http://creativecommons.org/licenses/by-nc/4.0/) which permits unrestricted non-commercial use, distribution, and reproduction in any medium, provided the original work is properly cited. 
However, little is known regarding how exercise-induced body composition changes HRV.

Many have reported that exercise training can alter parasympathetic activity (Facchini et al., 2003; Gutin et al., 1997; Gutin et al., 2005; Ito et al., 2001; Kiilavuori et al., 1995; Levy et al., 1998; Nagai and Moritani, 2004; Stein et al., 1999; Tian et al., 2015). In contrast, some researches have not shown such effect (Boutcher and Stein, 1995; Davy et al., 1997). The influence of exercise-induced HRV changes is controversial probably due to different exercise training programs and measures of HRV. In addition, most studies are cross sectional and have been conducted on children and adolescents (Gutin et al., 2000; Gutin et al., 2005; Lucini et al., 2013; Nagai and Moritani, 2004) or obese individuals with chronic diseases (Pagani and Lucini, 2001; Sjoberg et al., 2011). There has been very little research reported on the exercise-induced body composition and aerobic fitness changes HRV (Ito et al., 2001; Tian et al., 2015), particularly in obese sedentary young adults. There is also a lack of data in males (Ito et al., 2001). Therefore, this study attempted to clarify the casual link between the changes in body composition as well as in aerobic fitness and the alterations in cardiac autonomic modulation after a 12-week exercise training. Understanding how exercise-induced body composition and aerobic fitness alters HRV may lead to insights into the risks of CVD and a mean to predict the exercise adaptation in obese sedentary young adults.

\section{MATERIALS AND METHODS}

\section{Subjects and study design}

The randomized controlled trial conduced, for which 42 obese men aged 19 to 22 years with body mass index (BMI) $\geq 25 \mathrm{~kg} / \mathrm{m}^{2}$ and percentage of body fat $(\% \mathrm{BF})>24 \%$ (American College of Sports Medicine, 2010), were recruited. Subjects were no regular physical exercise in the last 6 months. Subjects were excluded if they had any clinical sign of CVD, neurological, musculoskeletal limitations to exercise or other overt chronic diseases, or current medication use. Subjects completed a Physical Activity Readiness Questionnaire (PAR-Q) before participating in the study. Subjects were informed of potential risks and the procedure of the study before they signed a written informed consent form. The study protocol was approved by the Kasetsart University Research Ethics Committee (COA61/033) and was conducted according to Declaration of Helsinki.

After the initial evaluation, the 20 eligible obese subjects (age, $20.5 \pm 1.2$ years; BMI, $31.4 \pm 5.2 \mathrm{~kg} / \mathrm{m}^{2} ; \% \mathrm{BF}, 30.0 \% \pm 6.5 \%$ ) were randomly assigned (1:1) to the exercise $(E G, n=10)$ or control $(C G, n=10)$ group, which were group-matched by age, BMI, and aerobic fitness. The EG group underwent a 12-week combined exercise training program with $4 \times 60$-min supervised sessions per week and was asked to maintain habitual diet throughout the study. The CG group did not participate in any weight control programs and was asked to maintain habitual diet and physical activity levels during the study. Measurements were performed in each subject at baseline and 1 week after the last exercise session. Anthropometrics and body composition, peak oxygen consumption $\left(\mathrm{VO}_{2 \text { peak }}\right)$, and resting $\mathrm{HRV}$ were measured at the same time of the day for each subject. Prior to test, subjects were asked to abstain from consumption of alcohol or caffeine-containing beverages for $24 \mathrm{hr}$. Smoking was also not allowed for at least $4 \mathrm{hr}$. To ensure consistent baseline activity levels, they were also instructed to avoid intense and/or prolonged exercise for 2 days.

\section{Exercise intervention}

The EG subjects participated in a $4 \times 60$-min sessions/wk of combined exercise program for 12 weeks and was assigned to increase energy expenditure by $452 \pm 48.1 \mathrm{kcal} / \mathrm{session}$ or $1,825 \pm$ $112.4 \mathrm{kcal} /$ week (Rippe and Hess, 1998). Training sessions consisted of $2 \times 30$-min sessions/wk with continuous moderate-intensity aerobic exercise (fast walking, jogging, ball games, or swimming) at an intensity between $50 \%$ to $70 \%$ of individual maximum heart rate $(\mathrm{HR} \max )$ and $10 \times 1$-min high-intensity interval training for 2 sessions/wk at an intensity between $80 \%$ to $90 \%$ of HRmax and interspersed with 2 min of recovery, followed by 20 min of strengthening exercises and 10 min of stretching and cooldown. The strengthening exercises were consisted of 2 to 3 series of 10 to 15 repetitions of the arms, legs, and trunk. The strengthening period was determined by the subject's body weight. HR was monitored continuously during each training session using a HR monitor (Forerunner 220, Garmin Ltd., Schaffhausen, Switzerland) and work rate was adjusted to maintain target HR. The training sessions were carefully supervised by experienced trainers. In addition, besides the supervised training sessions, the EG subjects received a recommendation to undergo unsupervised physical activity (by walking 30 min every day). The frequency and duration of unsupervised activities were assessed by a weekly recall questionnaire. The CG subjects did not participate in any intervention and was asked to maintain their habitual diet and physical activity levels throughout the study. 


\section{Anthropometrics and body composition measurements}

Body mass and body composition, including \% BF, fat mass (FM), and fat free mass (FFM), were measured using a bioimpedance analysis device (Inbody 720, Biospace Inc., Seoul, Korea) with light clothing and without shoes. Height was measured without shoes using a standard stadiometer (Health o Meter Professional, Sunbeam Products Inc., Boca Raton, FL, USA). The BMI was calculated as body mass divided by height squared $\left(\mathrm{kg} / \mathrm{m}^{2}\right)$. Waist circumference $(\mathrm{W})$ was measured form midway between the lower rib margin and the iliac crest at the end of inspiration, using a flexible and inextensible measuring tape (Hoechstmass Balzer $\mathrm{GmbH}$, Sulzbach, Hessen, Germany). Hip circumference $(\mathrm{H})$ was also measured at the level of trochanter major and the waist-to-hip circumferences $(\mathrm{W} / \mathrm{H})$ ratio was calculated.

\section{$\mathrm{VO}_{2 \text { peak }}$ measurement}

The $\mathrm{VO}_{2 \text { paak }}$ was measured with an incremental exercise test on an electromagnetically braked cycle ergometer (VIAsprint $150 \mathrm{P}$, Ergoline GmbH, Bitz, Germany). Briefly, the test was started at a 5 -min seated rest on the cycle ergometer, followed by $3 \mathrm{~min}$ of baseline unloaded cycling. The incremental protocol was initiated with a work rate of $50 \mathrm{~W}$, and the work rate was increased by 25 W every $2 \mathrm{~min}$. The subjects were encouraged to maintain the fixed pedaling frequency at 50 to $60 \mathrm{rev} / \mathrm{min}$ until volitional exhaustion, after which the subjects completed an unloaded recovery period of $3 \mathrm{~min}$. Expired gas samples were collected on a breathby-breath basis using a portable metabolic device (JAEGER Oxycon Mobile, CareFusion, Hoechberg, Germany), which was calibrated before each test using a 3-L syringe and known concentrations of oxygen $\left(15 \% \mathrm{O}_{2}\right)$ and carbon dioxide $\left(5 \% \mathrm{CO}_{2}\right)$. Oxygen consumption $\left(\mathrm{VO}_{2}\right)$, carbon dioxide production $\left(\mathrm{VCO}_{2}\right)$, and $\mathrm{HR}$ were continuously recorded and analyzed throughout the test. Arterial $\mathrm{O}_{2}$ saturation was continuously monitored using a fingertip pulse oximeter (OLV-3100K, Nihon Kohden, Tokyo, Japan). Rating of perceived exertion was obtained using the Borg scale (6-20) at the end of each work rate. Blood pressure (BP) was recorded using an automatic sphygmomanometer (Tango M2, SunTech Medical Inc., Morrisville, NC, USA) in the last 30 sec of each workload. The $\mathrm{VO}_{2 \text { peak }}$ was defined as the highest 30 -sec average value of $\mathrm{VO}_{2}$. The $\mathrm{VO}_{2 \text { peak }}$ was achieved when at least three of the following four criteria were met: (a) a plateau in $\mathrm{VO}_{2}$ despite an increasing work load, (b) a respiratory exchange ratio $>1.1$, (c) a HR within 10/min of HRmax, and (d) volitional exhaustion (Howley et al., 1995).

\section{$H R V$ recordings and analysis}

The RR intervals were recorded using a 5-min electrocardiogram (ECG) recording (eMotion Faros device, Mega Electronics, Kuopio, Finland) in lying position. The ECG recording was collected online at a sampling rate of $1,000 \mathrm{~Hz}$, in real time, and stored on a computer. The ECG recording took place at a fixed time in the morning (between 8:00 a.m. and 10:00 a.m.) to avoid possible circadian influences on autonomic function. Prior to the recording, subjects rested comfortably supine for at least $20 \mathrm{~min}$ in a quiet air-conditioned room with a room humidity and temperature of $67 \% \pm 1.8 \%$ and $25^{\circ} \mathrm{C} \pm 1.1^{\circ} \mathrm{C}$, respectively. The respiratory rate, determined by visual inspection of chest movement, was within the normal range (12-20/min).

The RR intervals were analyzed via a software program using the recommendations of the Task Force of the European Society of Cardiology and the North American Society of Pacing and Electrophysiology (Task Force of the European Society of Cardiology and the North American Society of Pacing and Electrophysiology, 1996). Time- and frequency-domain parameters together with the Poincare' plot or nonlinear components of HRV were calculated. The time-domain parameters consisted of mean RR intervals, standard deviation of all normal RR intervals (SDNN) and squared differences between adjacent normal NN intervals (RMSSD). The mean RR intervals and the SDNN provided information on sympathetic and parasympathetic cardiac modulation, and the RMSSD subsequently provided information on parasympathetic cardiac modulation. The frequency-domain parameters consisted of low frequency power (LF power: $0.04-0.15 \mathrm{~Hz}$ ) and high-frequency power (HF power: $0.15-0.4 \mathrm{~Hz}$ ) and the low-frequency/highfrequency $(\mathrm{LF} / \mathrm{HF})$ ratio. The LF power indicated sympathetic and vagal modulations simultaneously, the HF power indicated cardiac vagal modulation, and the LF/HF ratio indicated cardiac sympathetic-vagal balance ( $\mathrm{Ca}^{*}$ /Poincaré plot is a method to illustrate non-linear HRV components. Poincare' parameters, SD1 (Poincaré plot standard deviation perpendicular the line of identity) and SD2 (Poincaré plot standard deviation along the line of identity), were analyzed quantitatively by calculating the standard deviations from the RR interval data. The SD1 related to the fast beat-to-beat variability, while the SD2 described the longer-term variability. The SD1/SD2 ratio reflected non-linear components of HRV (Rajendra Acharya et al., 2006; Tulppo et al., 1996).

\section{Statistical analysis}

All data are presented as mean \pm standard devaiton. Normality of data distribution was assessed using the Shapiro-Wilk normal- 
ity tests. HRV variables with skewed distribution were log-transformed using the natural logarithm (ln). A paired $t$-test was used for the within-group comparisons. The difference between groups was compared by analysis of covariance, with adjustment for baseline values. Correlations among changes $(\Delta ; 12$-week value - baseline value) of $\mathrm{HRV}$ variables and adiposity measures, and aerobic fitness were performed using Pearson correlation. Stepwise linear regression analysis was also used to predict the variation in each of HRV indexes using the adiposity measures and the aerobic fitness as independent variables. Statistical analyses were performed using IBM SPSS Statistics ver. 20.0 (IBM Co., Armonk, NY, USA). Significant differences were defined as $P<0.05$.

\section{RESULTS}

All subjects completed the 12-week combined exercise program. According to BMI (The Asian-Pacific criteria), $45 \%$ of subjects were classified as obese I $\left(25 \mathrm{~kg} / \mathrm{m}^{2}<\mathrm{BMI}<30 \mathrm{~kg} / \mathrm{m}^{2}\right)$ and $55 \%$ as obese II $\left(\mathrm{BMI}>30 \mathrm{~kg} / \mathrm{m}^{2}\right)$. Forty percent of subjects

Table 1. Heart rate variability variables measured at baseline and after 12week exercise training

\begin{tabular}{lccccc}
\hline \multirow{2}{*}{ Variable } & \multicolumn{2}{c}{ CG $(\mathrm{n}=10)$} & & \multicolumn{2}{c}{$E G(\mathrm{n}=10)$} \\
\cline { 2 - 3 } \cline { 5 - 6 } & Baseline & 12 Weeks & & Baseline & 12 Weeks \\
\hline Resting HR (msec) & $67.8 \pm 6.1$ & $69.2 \pm 7.1$ & & $72.1 \pm 7.6$ & $66.3 \pm 3.7^{*,+}$ \\
Mean RR intervals & $6.8 \pm 0.1$ & $6.7 \pm 0.1$ & & $6.7 \pm 0.1$ & $6.8 \pm 0.1^{*,+}$ \\
(msec) & & & & \\
SDNN (msec) & $4.2 \pm 0.4$ & $4.1 \pm 0.5$ & & $4.2 \pm 0.3$ & $4.2 \pm 0.3$ \\
RMSSD (msec) & $3.9 \pm 0.9$ & $3.7 \pm 0.6$ & & $3.9 \pm 0.4$ & $3.9 \pm 0.3$ \\
pNN50 (\%) & $25.7 \pm 18.3$ & $27.2 \pm 24.0$ & & $30.2 \pm 16.6$ & $33.7 \pm 15.4$ \\
TP(msec ${ }^{2}$ ) & $8.1 \pm 0.9$ & $7.8 \pm 1.1$ & & $8.3 \pm 0.5$ & $8.1 \pm 7.2$ \\
HF (msec $\left.{ }^{2}\right)$ & $6.9 \pm 1.1$ & $6.3 \pm 1.3$ & & $6.7 \pm 0.9$ & $6.9 \pm 0.1$ \\
HF (nu) & $30.6 \pm 12.3$ & $24.8 \pm 11.9$ & & $24.6 \pm 14.0$ & $33.0 \pm 12.6^{*,+}$ \\
LF (msec ${ }^{2}$ ) & $7.2 \pm 1.0$ & $6.9 \pm 1.2$ & & $7.3 \pm 0.8$ & $6.8 \pm 1.4^{*}$ \\
LF (nu) & $40.8 \pm 16.2$ & $41.2 \pm 17.7$ & & $39.3 \pm 18.2$ & $38.2 \pm 14.2$ \\
LF/HF ratio & $1.9 \pm 2.2$ & $2.6 \pm 3.1$ & & $2.4 \pm 2.1$ & $1.7 \pm 1.5^{* *,+}$ \\
SD1 & $47.0 \pm 30.6$ & $35.6 \pm 25.7$ & & $38.2 \pm 12.0$ & $38.3 \pm 13.0$ \\
SD2 & $94.0 \pm 36.5$ & $85.7 \pm 43.3$ & & $92.8 \pm 21.4$ & $88.1 \pm 24.6^{* *}$ \\
SD1/SD2 ratio & $0.5 \pm 0.2$ & $0.4 \pm 0.1$ & & $0.4 \pm 0.1$ & $0.4 \pm 0.1$ \\
\hline
\end{tabular}

Values are presented as mean \pm standard deviation.

CG, control group; EG, exercise group; HR, heart rate; SDNN, standard deviation of normal RR intervals; RMSSD, squared differences between adjacent normal NN intervals; pNN50, percentage difference between adjacent normal RR intervals $>50$ msec; TP, total power; HF, high-frequency power; LF, low-frequency power; LF/HF ratio, low-frequency to high-frequency ratio; SD1, Poincaré plot standard deviation perpendicular the line of identity; SD2, Poincaré plot standard deviation along the line of identity.

${ }^{*} P<0.05$, ${ }^{*} P<0.01$, significant difference from baseline within group. ${ }^{\dagger} P<0.05$, significant difference in mean change between groups. had waist circumference over $100 \mathrm{~cm}$ and $60 \%$ had waist circumference between 90 and $100 \mathrm{~cm}$. The mean visceral fat area was $117 \pm 48.7 \mathrm{~cm}^{2}$. None of the subjects were current smokers. No baseline differences between groups were observed for age, body composition, BP, aerobic fitness, HRV, habitual dietary intake, physical activity levels, or clinical conditions.

\section{Effects of combined exercise training}

Body mass $(P<0.05)$, BMI $(P<0.01)$, FM $(P<0.01)$, W $(P<$ $0.01), \mathrm{H}(P<0.01)$, and $\mathrm{W} / \mathrm{H}$ ratio $(P<0.01)$ were significantly reduced in the EG group following the 12-week combined exercise training as compared to baseline levels. Meanwhile, there were no significant differences in any anthropometry or body composition variables in the $\mathrm{CG}$ group as compared to baseline levels. In the EG group, the mean reduction in body mass $(P<0.01)$, BMI $(P<0.01), \mathrm{FM}(P<0.05), \mathrm{W}(P<0.01), \mathrm{H}(P<0.05)$, and $\mathrm{W} / \mathrm{H}$ ratio $(P<0.05)$ following the 12 -week combined exercise training were significantly different from the CG group. The absolute $(P<$ $0.01)$ and relative $\mathrm{VO}_{2 \text { peak }}(P<0.01)$ following the 12 -week combined exercise training increased significantly in the EG group compared to baseline values. Meanwhile, there was no significant difference in $\mathrm{VO}_{2 \text { peak }}$ in the $\mathrm{CG}$ group compared to baseline values (Table 1). In the EG group, the mean improvements in absolute $(P<0.01)$ and relative $\mathrm{VO}_{2 \text { peak }}(P<0.01)$ following the 12 -week

Table 2. Adiposity and cardiorespiratory fitness measured at baseline and after 12-week exercise training

\begin{tabular}{lccccc}
\hline \multirow{2}{*}{ Variable } & \multicolumn{2}{c}{ CG $(\mathrm{n}=10)$} & & \multicolumn{2}{c}{ EG $(\mathrm{n}=10)$} \\
\cline { 2 - 3 } \cline { 5 - 6 } & Baseline & 12 Weeks & & Baseline & 12 Weeks \\
\hline Age $(\mathrm{yr})$ & $20.7 \pm 1.2$ & - & & $20.3 \pm 1.3$ & - \\
Height $(\mathrm{cm})$ & $174.6 \pm 5.7$ & - & & $174 \pm 6.6$ & - \\
Body mass $(\mathrm{kg})$ & $97.8 \pm 19.6$ & $97.8 \pm 19.6$ & & $97.8 \pm 19.6$ & $97.8 \pm 19.6^{* *, t+}$ \\
BMl $\left(\mathrm{kg} / \mathrm{m}^{2}\right)$ & $31.4 \pm 5.3$ & $31.4 \pm 5.3$ & & $31.4 \pm 5.3$ & $31.4 \pm 5.3^{* *, t+}$ \\
Body fat $(\%)$ & $29.6 \pm 13.4$ & $29.9 \pm 13.3$ & & $30.5 \pm 13.5$ & $28.6 \pm 13.5$ \\
Fat mass $(\mathrm{kg})$ & $68.7 \pm 8.2$ & $69.0 \pm 9.0$ & & $65.0 \pm 8.9$ & $65.0 \pm 8.0^{* *, t}$ \\
FFM $(\mathrm{kg})$ & $39.3 \pm 5.0$ & $39.5 \pm 5.6$ & & $37.1 \pm 5.1$ & $37.3 \pm 4.5$ \\
W $(\mathrm{cm})$ & $100.9 \pm 15.6$ & $102.3 \pm 15.8$ & & $100.2 \pm 15.2$ & $97.7 \pm 14.7^{* *, t+}$ \\
$\mathrm{H}(\mathrm{cm})$ & $112.7 \pm 8.5$ & $112.6 \pm 9.5$ & & $111.2 \pm 10.5$ & $108.1 \pm 11.0^{* *, t}$ \\
W/H ratio & $0.91 \pm 0.04$ & $0.91 \pm 0.04$ & & $0.91 \pm 0.04$ & $0.90 \pm 0.04^{* *, t}$ \\
VO $_{2 \text { peak }}(\mathrm{L} / \mathrm{min})$ & $2.6 \pm 0.4$ & $2.6 \pm 0.4$ & & $2.5 \pm 0.3$ & $2.8 \pm 0.3^{* *, t+}$ \\
VO $_{2 \text { peak }}(\mathrm{mL} / \mathrm{kg} / \mathrm{min})$ & $27.1 \pm 5.3$ & $27.0 \pm 5.4$ & & $26.9 \pm 5.4$ & $30.5 \pm 4.6^{* *, t+}$ \\
\hline
\end{tabular}

Values are presented as mean \pm standard deviation.

CG, control group; EG, exercise group; BMI, body mass index; FFM, fat free mass; SMM, skeletal muscle mass; $W$, waist circumference; $H$, hip circumference; $W / H$ ratio, waist to hip circumference; $\mathrm{VO}_{2 \text { peak, }}$, peak oxygen consumption.

${ }^{* *} P<0.01$, significant difference from baseline within group. ${ }^{\dagger} P<0.05,{ }^{{ }^{\dagger}} P<0.01$, significant difference in mean change between groups. 
combined exercise training were significantly different from the CG group (Table 2).

The HRV variables following exercise training are presented in Table 1 . Mean RR intervals $(P<0.05)$ and normalized values of
HF $(P<0.05)$ following the 12-week combined exercise training increased significantly, while resting $\operatorname{HR}(P<0.05), \mathrm{LF}\left(\ln \mathrm{msec}^{2}\right)$ $(P<0.01), \mathrm{LF} / \mathrm{HF}$ ratio $(P<0.05)$, and SD2 $(P<0.01)$ following the 12-week combined exercise training was significantly reduced

Table 3. Correlation coefficients $(r)$ of changes between adiposity indices and aerobic fitness and heart rate variability variables

\begin{tabular}{|c|c|c|c|c|c|c|c|c|c|c|c|}
\hline Variable & $\begin{array}{c}\Delta \text { RR intervals } \\
\quad \text { (msec) }\end{array}$ & $\begin{array}{c}\triangle \mathrm{SDNN} \\
\text { (msec) }\end{array}$ & $\begin{array}{c}\triangle \mathrm{RMSSD} \\
\text { (msec) }\end{array}$ & $\begin{array}{c}\Delta p N N 50 \\
(\%)\end{array}$ & $\begin{array}{c}\Delta \mathrm{TP} \\
\left(\mathrm{msec}^{2}\right)\end{array}$ & $\begin{array}{c}\Delta \mathrm{HF} \\
\left(\mathrm{msec}^{2}\right)\end{array}$ & $\begin{array}{l}\Delta H F \\
\text { (nu) }\end{array}$ & $\begin{array}{c}\Delta \mathrm{LF} \\
\left(\mathrm{msec}^{2}\right)\end{array}$ & $\begin{array}{l}\Delta \mathrm{LF} \\
\text { (nu) }\end{array}$ & $\begin{array}{c}\Delta(\mathrm{LF} / \mathrm{HF}) \\
\text { ratio }\end{array}$ & $\begin{array}{l}\Delta(S D 1 / S D 2) \\
\text { ratio }\end{array}$ \\
\hline$\Delta$ Body mass (kg) & -0.411 & -0.186 & -0.112 & 0.093 & 0.033 & -0.129 & -0.234 & -0.145 & -0.401 & -0.024 & 0.051 \\
\hline$\Delta \mathrm{BMI}\left(\mathrm{kg} / \mathrm{m}^{2}\right)$ & -0.406 & -0.117 & -0.092 & 0.082 & 0.077 & -0.092 & -0.259 & -0.081 & -0.286 & 0.008 & 0.050 \\
\hline$\Delta$ Body fat $(\%)$ & -0.397 & -0.078 & 0.032 & 0.050 & -0.058 & -0.137 & -0.132 & -0.151 & -0.170 & -0.015 & 0.121 \\
\hline$\Delta$ Fat mass $(\mathrm{kg})$ & $-0.502^{*}$ & -0.071 & 0.008 & 0.073 & -0.007 & -0.134 & -0.211 & -0.138 & -0.258 & -0.026 & 0.124 \\
\hline$\Delta \mathrm{FFM}(\mathrm{kg})$ & 0.085 & -0.065 & -0.109 & 0.015 & 0.080 & 0.024 & -0.056 & 0.050 & -0.024 & 0.064 & -0.087 \\
\hline$\Delta \mathrm{W}(\mathrm{cm})$ & -0.113 & -0.013 & 0.059 & $0.495^{*}$ & 0.016 & -0.202 & -0.378 & -0.185 & -0.020 & 0.213 & 0.103 \\
\hline$\Delta(\mathrm{W} / \mathrm{H}$ ratio $)$ & $-0.450^{*}$ & -0.068 & 0.028 & 0.045 & -0.029 & -0.109 & -0.101 & -0.165 & -0.284 & -0.066 & 0.117 \\
\hline$\Delta V O_{2 \text { peak }}(\mathrm{L} / \mathrm{min})$ & 0.153 & -0.001 & 0.169 & 0.360 & -0.033 & 0.240 & $0.459^{*}$ & -0.373 & -0.233 & $-0.444^{*}$ & $0.500^{* *}$ \\
\hline$\Delta V O_{2 \text { peak }}(\mathrm{mL} / \mathrm{kg} / \mathrm{min})$ & 0.225 & 0.100 & 0.270 & $0.471^{*}$ & 0.044 & 0.310 & $0.425^{*}$ & -0.349 & -0.212 & $-0.470^{*}$ & $0.570^{* *}$ \\
\hline
\end{tabular}

Absolute change ( $\Delta ; 12$-week value - baseline value).

$\mathrm{BMI}$, body mass index; FFM, fat free mass; $\mathrm{W}$, waist circumference; $\mathrm{W} / \mathrm{H}$ ratio, waist to hip circumference; $\mathrm{VO}_{2 \text { peak, }}$ peak oxygen consumption; $\mathrm{SDNN}$, standard deviation of normal RR intervals; RMSSD, square root of the mean squared difference between adjacent normal RR intervals; pNN50, percentage difference between adjacent normal RR intervals > 50 msec; TP, total power; HF, high-frequency power; LF, low-frequency power; LF/HF, low-frequency to high-frequency ratio; SD1, Poincaré plot standard deviation perpendicular the line of identity; SD2, Poincaré plot standard deviation along the line of identity. $\mathrm{n}=20 .{ }^{*} P<0.05 .{ }^{*} P<0.01$.
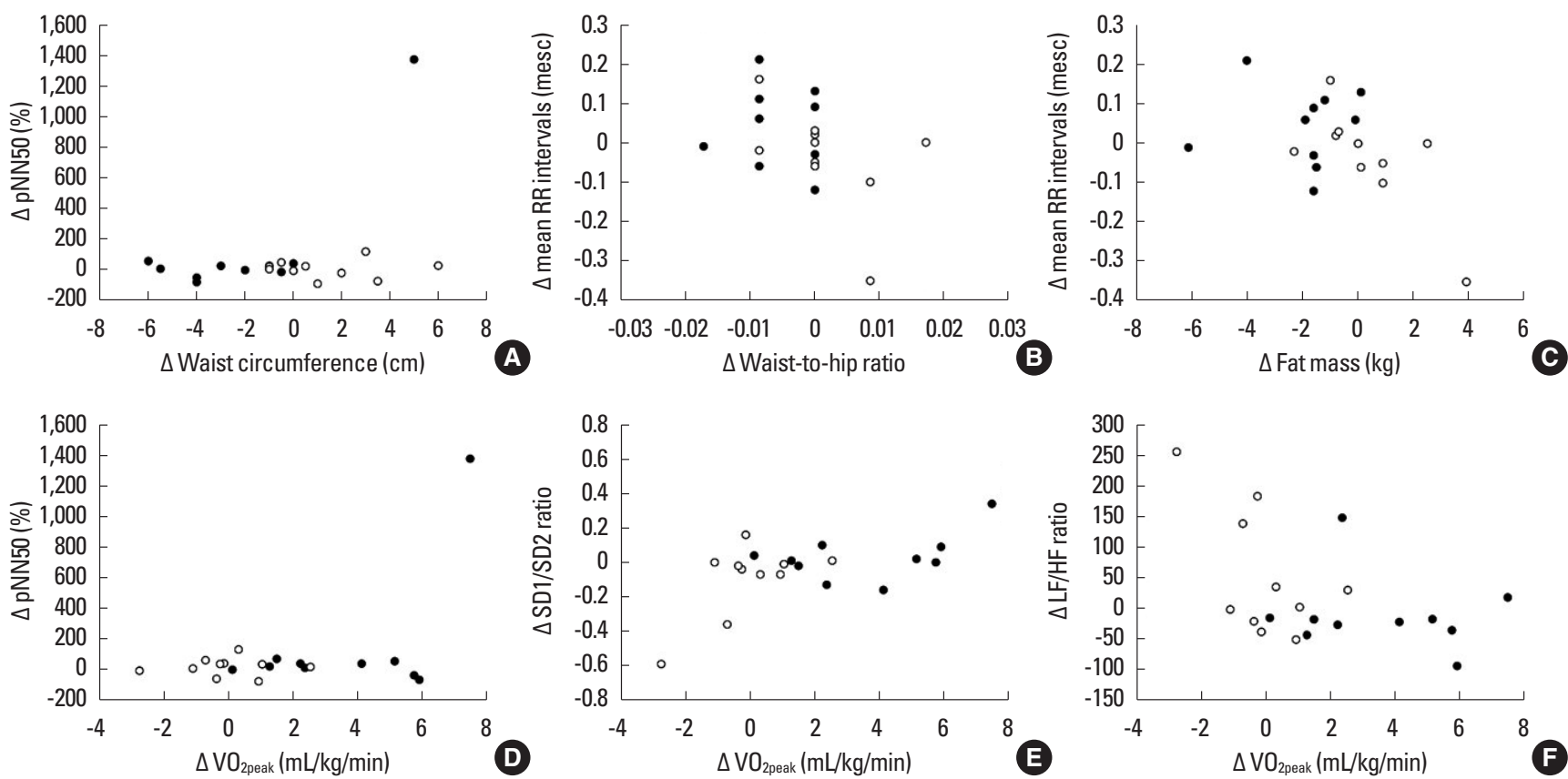

Fig. 1. Correlation between (A) the change in waist circumference and the change in pNN50 $(r=0.495, P<0.05)$, (B) the change in waist-to-hip ratio and the change in mean $\mathrm{RR}$ intervals $(r=-0.045, P<0.05)$, (C) the change in fat mass and the change in mean RR intervals $(r=-0.502, P<0.05)$, (D) the change in relative V0 $0_{2 p e a k}$ and the change in pNN50 $(r=0.471, P<0.05)$, (E) the change in relative $V_{2 \text { peak }}$ and the change in the SD1/SD2 Poincaré plot index $(r=0.57, P<0.01)$, (F) the change in relative $\mathrm{VO}_{2 \text { peak }}$ and the change in the LF/HF ratio $(r=-0.444, P<0.05)$. $\bullet$, EG group; $\circ, \mathrm{CG}$ group; pNN50, percentage of successive RR intervals that differ by more than 50 msec; SD1, Poincaré plot standard deviation perpendicular the line of identity; SD2, Poincaré plot standard deviation along the line of identity; LF, low-frequency; $\mathrm{HF}$, high-frequency; $\mathrm{VO}_{\text {2peak, }}$ peak oxygen consumption. 
Table 4. Stepwise liner regression analysis for factors associated with the relative $\mathrm{VO}_{2 \text { peak }}$

\begin{tabular}{|c|c|c|c|c|c|c|c|}
\hline & \multicolumn{7}{|c|}{ Changes in $\mathrm{VO}_{2 \text { peak }}(\mathrm{mL} / \mathrm{kg} / \mathrm{min})$} \\
\hline & \multicolumn{2}{|c|}{ Unstandardized coefficients } & \multirow{2}{*}{$\begin{array}{l}\text { Standardized coeffi- } \\
\quad \text { cients }(\beta)\end{array}$} & \multirow{2}{*}{$t$} & \multirow{2}{*}{$P$-value } & \multirow{2}{*}{$R$} & \multirow{2}{*}{$R^{2}$} \\
\hline & B & SEM & & & & & \\
\hline Constant & 2.039 & 0.516 & - & 3.953 & 0.001 & - & - \\
\hline$\Delta S D 1 / S D 2$ ratio & 8.141 & 2.769 & 0.570 & 2.940 & 0.009 & $0.570^{* *}$ & $0.324^{* *}$ \\
\hline
\end{tabular}

$\mathrm{VO}_{2 \text { peak, }}$ peak oxygen consumption; SD1, Poincaré plot standard deviation perpendicular the line of identity; SD2, Poincaré plot standard deviation along the line of identity; SEM, standard error of the mean.

${ }^{* *} P<0.01$

in the EG group compared to baseline values. Meanwhile, there was no significant difference found in any of the HRV variables in the $\mathrm{CG}$ group compared to baseline values. In the EG group, the increase in mean RR intervals $(P<0.05)$ and normalized HF $(P<$ $0.05)$ and the reduction in resting $\mathrm{HR}(P<0.05)$ and $\mathrm{LF} / \mathrm{HF}$ ratio $(P<0.05)$ following the 12 -week combined exercise training were significantly different from the CG group (Table 1).

\section{Correlation between the changes in $\mathrm{HRV}$ and the changes in adiposity indices and aerobic fitness over the training period}

The correlation coefficients $(r)$ for changes between HRV variables and adiposity indices and aerobic fitness are presented in Table 3. Pearson correlation between the changes in adiposity and HRV changes showed significant positive correlation of $\mathrm{W}$ changes with $\Delta$ pNN50 $(r=0.495, P<0.05)$ (Fig. $1 \mathrm{~A})$, and negative correlation of $\mathrm{W} / \mathrm{H}$ ratio $(r=-0.450, P<0.05)$ (Fig. 1B) and FM changes $(r=$ $-0.502, P<0.05)$ with $\Delta$ mean $\mathrm{RR}$ intervals (ln msec) (Fig.1C). Significant positive correlations were observed between changes of $\mathrm{VO}_{2 \text { peak }}$ and $\Delta \mathrm{pNN} 50(r=0.471, P<0.05)$ (Fig. 1D), and $\Delta$ HFnu $(r=0.425, P<0.05)$, and $\Delta \mathrm{SD} 1 / \mathrm{SD} 2$ ratio $(r=0.570, P<0.01)$ (Fig. 1E). Meanwhile, the changes of $\mathrm{VO}_{2 \text { peak }}$ and $\Delta \mathrm{LF} / \mathrm{HF}$ ratio $(r=-0.470, P<0.05)$ (Fig. $1 \mathrm{~F})$ showed significant negative correlation (Table 3).

Subjects with greater individual changes in vagal-related HRV variables had more reduction in central obesity, $\mathrm{W}$ and $\mathrm{W} / \mathrm{H}$ ratio, and a greater increase in $\mathrm{VO}_{\text {2peak }}$ over the training period (Fig. 1). The results of the multiple stepwise regression analysis revealed that only the changes in SD1/SD2 ratio explained a significant proportion of the variance in the relative $\mathrm{VO}_{2 \text { peak }}$ changes $\left(R^{2}=0.324, P<0.01\right)($ Table 4).

\section{DISCUSSION}

Our results indicate that vagal activity improves with fat loss and increased aerobic fitness after the exercise training in obese sedentary young men. Changes of the vagal-related HRV variables were significantly related to fat loss. Moreover, the subjects with a greater sympathovagal balance had greater improvement in the aerobic fitness (relative $\mathrm{VO}_{\text {2peak }}$ ). These finding suggest that the alteration in resting HRV, especially the SD1/SD2 ratio is a possible predictor for adaptations to exercise training in obese sedentary young men.

Obesity is associated with dysregulation of cardiac autonomic function and rises the risks of CVD. The cardiac autonomic dysfunction has been attributed to excess fat and weight gain (Sheema and Malipatil, 2015). Our findings indicate that the higher reduction in FM and central obesity (measured by $\mathrm{W}$ and $\mathrm{W} / \mathrm{H}$ ratio), the greater alteration of vagal-related $H R V$ variables (mean $R R$ intervals and pNN50). Our study confirms the results of previous studies in which cardiac parasympathetic activity increased with fat loss after exercise training (Tian et al., 2015). It was difficult to compare our results with the previous study because our subjects were all men, whereas the other analyzed men and women together (Tian et al., 2015). It has been suggested that gender influences HRV; healthy men at age $<30$ years have been reported to have greater HRV variables than women, and age also affects cardiac autonomic control of HR (Umetani et al., 1998). A previous study (Rissanen et al., 2001) reported that the vagal activity related to a large weight loss by an average of $9.5 \%(8.7 \mathrm{~kg})$. However, in our present study, the vagal-related HRV variables correlated to the reduction in FM and central obesity instead of the weight loss $(2.3 \%$ or $2.2 \mathrm{~kg})$. The interindividual differences in mean RR intervals with fat loss $(6.6 \%$ or $2 \mathrm{~kg})$ were observed in this study. Indeed, the changes in central obesity (measured by $\mathrm{W}$ and $\mathrm{W} / \mathrm{H}$ ratio) correlated with changes in vagal-related $\mathrm{HRV}$ variables (mean $\mathrm{RR}$ intervals and $\mathrm{pNN50)}$. The more central fat loss, the more increased vagal activity. Obese individuals with higher central fat were sympathovagal imbalance compared to those with lower central fat (Soares-Miranda et al., 2011). Another study confirmed the improvements in vagal-related HRV variables elicited by exercise training correlated with altered trunk fat percentage and/or 
W in overweight and obese adults (Tian et al., 2015). Thus, the regional fat distribution might contribute to the individual differences in HRV response (Chen et al., 2008). These finding demonstrate that central obesity influences vagal activity after exercise training. Although weight reduction in obese subjects has been suggested to improve parasympathetic activity (Karason et al., 1999; Rissanen et al., 2001), such effect was not observed in (Minami et al., 1999). Thus, the casual link between weight loss and beneficial alterations in cardiac autonomic function is still unclear. In addition, influence of continuous endurance training with moderate intensity on resting HRV was not observed in obese women without fat loss (Figueroa et al., 2007). Nevertheless, such influence of a progressive-intensity training was observed with fat loss (Tian et al., 2015). In our study, an improved vagal-related HRV variables was observed after the exercise training in obese sedentary young men with fat loss. This might demonstrate a correlation between the fat loss due to exercise training and the improved HRV. The vagal-related HRV variables appear to be influenced in individuals with fat loss, especially central fat in our study. However, low $\mathrm{R}$-squared values $\left(R^{2}=0.252, P<0.05\right)$ revealed that reduced FM does not fully explain the improvement in HRV. Alterations of potential contributing factors might be involved, such as insulin resistance (Lindmark et al., 2005), leptin (Quilliot et al., 2008), and inflammation (Akinci et al., 2008).

Low aerobic fitness and abnormalities of cardiac autonomic modulation are significant contributors to increased CVD risk in obese individuals (Grassi et al., 2004; Oktay et al., 2017; Piccirillo et al., 1998; Wei et al., 1999). Our findings indicate that the 12-week combined exercise training program is able to improve aerobic fitness and to favorably modify sympathovagal balance, with increases in mean RR intervals and normalized HF and decreases in resting $\mathrm{HR}$ and the $\mathrm{LF} / \mathrm{HF}$ ratio. These findings are consistent with previous studies supporting the idea that training improves autonomic function (Buchheit and Gindre, 2006; Tian et al., 2015; Vesterinen et al., 2013). Interestingly, the reduction in resting HR may explain why we observed significant increases in normalized HF values and a reduction in the LF/HF ratio, as the variables are primarily mediated by $R R$ intervals. It has been suggested that lower resting HR can result from an increase in vagal and a reduction in sympathetic outflow. The adaptations to exercise training appear to affect both branches of the autonomic nervous system (ANS) (Carter et al., 2003). Our findings are consistent with the improvement in sympathovagal balance after the exercise training already suggested by the HRV variables (mean $\mathrm{RR}$ intervals, HFnu, and LF/HF ratio). The reduction in resting
HR possibly contributes to the improvement observed in aerobic fitness (Buchheit and Gindre, 2006; Facchini et al., 2003). Our results confirm that moderately strong correlations were found between the changes in pNN50, HFnu, LF/HF ratio, and SD1/ $\mathrm{SD} 2$ ratio versus the increased in aerobic fitness. These associations concur with previous studies which revealed that higher aerobic fitness is associated with a higher vagal cardiac control (Carter et al., 2003; Grant et al., 2013; Nagai and Moritani, 2004). Increased parasympathetic and decreased sympathetic outflow to the heart elicited by exercise training is typically considered a factor in cardioprotection (Billman and Kukielka, 2007). Our findings are supported by the stepwise regression analysis revealing that changes in the SD1/SD2 ratio can predict $32.4 \%$ of the variance in the relative $\mathrm{VO}_{\text {2peak }}$ changes. The SD1/SD2 ratio is the most important predictor of changes in aerobic fitness elicited by exercise training. The SD1 indicates the parasympathetic activity, the $\mathrm{SD} 2$ indicates the sympathetic modulation, and the SD1/SD2 ratio indicates the sympathovagal balance (Shaffer and Ginsberg, 2017). Moreover, the high SD1/SD2 ratio can be used as an indicator of healthy cardiac dynamics (Shaffer and Ginsberg, 2017). As the SD1/SD2 ratio is proposed to be a good measure of sympathovagal balance, it can be assumed that an increased parasympathetic and a decreased sympathetic outflow to the heart may be related to improved performance.

To our knowledge, this is the first study detailing the effect of exercise training in the ANS response to fat loss and aerobic capacity in obese sedentary young men. Sympathovagal balance elicited by the exercise training correlated with fat loss and aerobic fitness. These findings appeared to support a concept of cardiovascular protection that regular physical activity could reduce mortality and morbidity of CVD. Moreover, our results suggested that resting HRV, especially the SD1/SD2 ratio, might be a predictor of CRF in overweight and obese young men. However, the study had limitations. The number of subjects was small. Furthermore, there were no data in females; neither were sex-related differences in HRV studied.

These findings suggested that obese sedentary young men achieved significant improvements in vagal activity, adiposity indices and aerobic fitness after 12 weeks of the combined exercise training. The improvements in vagal activity elicited by the exercise training program correlated with fat loss in obese sedentary young men. Moreover, the subjects with a greater sympathovagal balance had greater improvement in the aerobic fitness. These finding suggest that the alteration in resting HRV is a possible predictor for adaptations to exercise training in obese sedentary 
young men.

\section{CONFLICT OF INTEREST}

No potential conflict of interest relevant to this article was reported.

\section{ACKNOWLEDGMENTS}

The authors would like to thank the Exercise and Sport Sciences Development and Research Group, Khon Kaen University, Khon Kaen, Thailand. The authors would also like to thank the participants for their enthusiastic participation in this study.

\section{REFERENCES}

Aekplakorn W, Mo-Suwan L. Prevalence of obesity in Thailand. Obes Rev 2009;10:589-592.

Akinci G, Akinci B, Coskun S, Bayindir P, Hekimsoy Z, Ozmen B. Evaluation of markers of inflammation, insulin resistance and endothelial dysfunction in children at risk for overweight. Hormones (Athens) 2008;7:156-162.

American College of Sports Medicine. ACSM's guidelines for graded exercise testing and prescription. 8th ed. Philadelphia (PA): Lippincott Williams \& Wilkins; 2010

Billman GE, Kukielka M. Effect of endurance exercise training on heart rate onset and heart rate recovery responses to submaximal exercise in animals susceptible to ventricular fibrillation. J Appl Physiol (1985) 2007;102:231-240

Boutcher SH, Stein P. Association between heart rate variability and training response in sedentary middle-aged men. Eur J Appl Physiol Occup Physiol 1995;70:75-80.

Buchheit M, Gindre C. Cardiac parasympathetic regulation: respective associations with cardiorespiratory fitness and training load. Am J Physiol Heart Circ Physiol 2006;291:H451-458.

Carter JB, Banister EW, Blaber AP. Effect of endurance exercise on autonomic control of heart rate. Sports Med 2003;33:33-46.

Chen GY, Hsiao TJ, Lo HM, Kuo CD. Abdominal obesity is associated with autonomic nervous derangement in healthy Asian obese subjects. Clin Nutr 2008;27:212-217.

Davy KP, Willis WL, Seals DR. Influence of exercise training on heart rate variability in post-menopausal women with elevated arterial blood pressure. Clin Physiol 1997;17:31-40.

Facchini M, Malfatto G, Sala L, Silvestri G, Fontana P, Lafortuna C, Sartorio $\mathrm{A}$. Changes of autonomic cardiac profile after a 3-week integrated body weight reduction program in severely obese patients. J Endocrinol Invest 2003;26:138-142.

Figueroa A, Baynard T, Fernhall B, Carhart R, Kanaley JA. Endurance training improves post-exercise cardiac autonomic modulation in obese women with and without type 2 diabetes. Eur J Appl Physiol 2007;100:437-444.

Grant CC, Murray C, Janse van Rensburg DC, Fletcher L. A comparison between heart rate and heart rate variability as indicators of cardiac health and fitness. Front Physiol 2013;4:337.

Grassi G, Dell'Oro R, Facchini A, Quarti Trevano F, Bolla GB, Mancia G. Effect of central and peripheral body fat distribution on sympathetic and baroreflex function in obese normotensives. J Hypertens 2004;22: 2363-2369.

Gutin B, Barbeau P, Litaker MS, Ferguson M, Owens S. Heart rate variability in obese children: relations to total body and visceral adiposity, and changes with physical training and detraining. Obes Res 2000;8: 12-19.

Gutin B, Howe C, Johnson MH, Humphries MC, Snieder H, Barbeau P. Heart rate variability in adolescents: relations to physical activity, fitness, and adiposity. Med Sci Sports Exerc 2005;37:1856-1863.

Gutin B, Owens S, Slavens G, Riggs S, Treiber F. Effect of physical training on heart-period variability in obese children. J Pediatr 1997;130: 938-943.

Howley ET, Bassett DR Jr, Welch HG. Criteria for maximal oxygen uptake: review and commentary. Med Sci Sports Exerc 1995;27:1292-1301.

Ito H, Ohshima A, Tsuzuki M, Ohto N, Yanagawa M, Maruyama T, Kaji Y, Kanaya S, Nishioka K. Effects of increased physical activity and mild calorie restriction on heart rate variability in obese women. Jpn Heart J 2001;42:459-469.

Jensen MD, Ryan DH, Apovian CM, Ard JD, Comuzzie AG, Donato KA, Hu FB, Hubbard VS, Jakicic JM, Kushner RF, Loria CM, Millen BE, Nonas CA, Pi-Sunyer FX, Stevens J, Stevens VJ, Wadden TA, Wolfe BM, Yanovski SZ; American College of Cardiology/American Heart Association Task Force on Practice Guidelines; Obesity Society. 2013 AHA/ACC/TOS guideline for the management of overweight and obesity in adults: a report of the American College of Cardiology/ American Heart Association Task Force on Practice Guidelines and The Obesity Society. J Am Coll Cardiol 2014;63(25 Pt B):2985-3023.

Karason K, Mølgaard H, Wikstrand J, Sjöström L. Heart rate variability in obesity and the effect of weight loss. Am J Cardiol 1999;83:1242-1247.

Kiilavuori K, Toivonen L, Näveri H, Leinonen H. Reversal of autonomic derangements by physical training in chronic heart failure assessed by heart rate variability. Eur Heart J 1995;16:490-495.

Levy WC, Cerqueira MD, Harp GD, Johannessen KA, Abrass IB, Schwartz $\mathrm{RS}$, Stratton JR. Effect of endurance exercise training on heart rate vari- 
ability at rest in healthy young and older men. Am J Cardiol 1998;82: 1236-1241.

Lindmark S, Lönn L, Wiklund U, Tufvesson M, Olsson T, Eriksson JW. Dysregulation of the autonomic nervous system can be a link between visceral adiposity and insulin resistance. Obes Res 2005;13:717-728.

Lucini D, de Giacomi G, Tosi F, Malacarne M, Respizzi S, Pagani M. Altered cardiovascular autonomic regulation in overweight children engaged in regular physical activity. Heart 2013;99:376-381.

Minami J, Kawano Y, Ishimitsu T, Matsuoka H, Takishita S. Acute and chronic effects of a hypocaloric diet on 24-hour blood pressure, heart rate and heart-rate variability in mildly-to-moderately obese patients with essential hypertension. Clin Exp Hypertens 1999;21:1413-1427.

Nagai N, Moritani T. Effect of physical activity on autonomic nervous system function in lean and obese children. Int J Obes Relat Metab Disord 2004;28:27-33.

Oktay AA, Lavie CJ, Kokkinos PF, Parto P, Pandey A, Ventura HO. The interaction of cardiorespiratory fitness with obesity and the obesity paradox in cardiovascular disease. Prog Cardiovasc Dis 2017;60:30-44.

Pagani M, Lucini D. Autonomic dysregulation in essential hypertension: insight from heart rate and arterial pressure variability. Auton Neurosci 2001;90:76-82.

Piccirillo G, Vetta F, Viola E, Santagada E, Ronzoni S, Cacciafesta M, Marigliano $\mathrm{V}$. Heart rate and blood pressure variability in obese normotensive subjects. Int J Obes Relat Metab Disord 1998;22:741-750.

Quilliot D, Böhme P, Zannad F, Ziegler O. Sympathetic-leptin relationship in obesity: effect of weight loss. Metabolism 2008;57:555-562.

Rajendra Acharya U, Paul Joseph K, Kannathal N, Lim CM, Suri JS. Heart rate variability: a review. Med Biol Eng Comput 2006;44:1031-1051.

Rippe JM, Hess S. The role of physical activity in the prevention and management of obesity. J Am Diet Assoc 1998;98(10 Suppl 2):S31-38.

Rissanen P, Franssila-Kallunki A, Rissanen A. Cardiac parasympathetic activity is increased by weight loss in healthy obese women. Obes Res 2001;9:637-643.

Shaffer F, Ginsberg JP. An overview of heart rate variability metrics and norms. Front Public Health 2017;5:258.

Sheema UK, Malipatil BS. A cross-sectional study on effect of body mass index on the spectral analysis of heart rate variability. Natl J Physiol Pharm Pharmacol 2015;5:250-252.

Sjoberg N, Brinkworth GD, Wycherley TP, Noakes M, Saint DA. Moderate weight loss improves heart rate variability in overweight and obese adults with type 2 diabetes. J Appl Physiol (1985) 2011;110:1060-1064.

Soares-Miranda L, Alves AJ, Vale S, Aires L, Santos R, Oliveira J, Mota J. Central fat influences cardiac autonomic function in obese and overweight girls. Pediatr Cardiol 2011;32:924-928.

Stein PK, Ehsani AA, Domitrovich PP, Kleiger RE, Rottman JN. Effect of exercise training on heart rate variability in healthy older adults. Am Heart J 1999;138(3 Pt 1):567-576.

Task Force of the European Society of Cardiology and the North American Society of Pacing and Electrophysiology. Heart rate variability: standards of measurement, physiological interpretation and clinical use. Circulation 1996;93:1043-1065.

Tian Y, Huang C, He Z, Hong P, Zhao J. Autonomic function responses to training: correlation with body composition changes. Physiol Behav 2015;151:308-313.

Tulppo MP, Mäkikallio TH, Takala TE, Seppänen T, Huikuri HV. Quantitative beat-to-beat analysis of heart rate dynamics during exercise. Am J Physiol 1996;271(1 Pt 2):H244-252.

Umetani K, Singer DH, McCraty R, Atkinson M. Twenty-four hour time domain heart rate variability and heart rate: relations to age and gender over nine decades. J Am Coll Cardiol 1998;31:593-601.

Vesterinen V, Häkkinen K, Hynynen E, Mikkola J, Hokka L, Nummela A. Heart rate variability in prediction of individual adaptation to endurance training in recreational endurance runners. Scand J Med Sci Sports 2013;23:171-180.

Wei M, Kampert JB, Barlow CE, Nichaman MZ, Gibbons LW, Paffenbarger RS Jr, Blair SN. Relationship between low cardiorespiratory fitness and mortality in normal-weight, overweight, and obese men. JAMA 1999;282:1547-1553. 